\title{
Collateral water drinking in rats maintained on FR food reinforcement schedules'
}

ROBERT W. SCHAEFFER AND JUDITH C. DIEHL

Six food-deprived female rats were tested on a bar press for food contingency under increasing $F R$ requirements. The results corroborated a prandial interpretation of scheduleinduced collateral water drinking in that number of meals, total water drunk, and amount of water ingested per reinforcement increased as the FR requirement increased.

Recent studies have shown that food-deprived rats tested on VI, FI, and DRL food reinforcement schedules consistently engage in excessive collateral water drinking (e.g., Falk, 1961, 1964; Segal \& Holloway, 1963; Stein, 1964). Increased water intake has also been observed in food-deprived rats tested on FR food reinforcement schedules in which the $F R$ requirements were as little as 33. Increased water intake, however, has been observed less consistently in the responsedependent FR schedules than in time-dependent VI, FI, and DRL schedules (cf. Falk, 1964; Clark, 1962; Stein, 1964). The factors responsible for this phenomenon are not understood; Stein (1964), however, has suggested that the effect is attributable to a schedule-induced thirst factor. Stein has argued that (1) the ingestion of dry food pellets induces thirst, (2) rats typically drink after ingesting some number of reinforcements, thereby signaling the end of a meal, (3) schedule requirements impose restrictive constraints upon the number of reinforcements ingested per meal, thereby increasing the number of meals eaten per session, (4) the net effect of the schedule-induced increase in number of meals is more frequent drinking and, consequently, increased water consumption. The purpose of the present study was to examine the effects of an increasing FR requirement, in a bar press for food contingency, upon meal frequency and water intake. If Stein's thesis is correct, progressive increases in the FR requirement should be accompanied by more frequent meals and increased water consumption.

\section{Method}

The Ss were six, 400 day old Sprague-Dawley female albino rats that had previously been used in an alternating acquisition and extinction study in which they bar-pressed for food on a CRF schedule. The previous study was terminated about four months prior to the beginning of the present study. During these four months, the Ss were maintained on ad lib food and water in the home cages.

The apparatus consisted of six Lehigh Valley rat test chambers with a $100 \mathrm{ml}$ graduated water tube installed in place of the right bar. Standard $45 \mathrm{mg}$ Noyes lab rat food pellets which were contingent upon bar pressing were used as reinforcers. Bar pressing and drinking responses were recorded by relay circuitry, drinkometers, counters, and an Esterline Angus digital operations recorder.

The Ss were first adapted in the home cage to a $21-\mathrm{hr}$. food deprivation schedule, then tested in daily $3-\mathrm{hr}$. sessions under FR1, FR5, FR10, FR20, FR40, and FR80 schedules, in that order. Food pellets were available only during the 3-hr. test sessions. Water was available on an ad lib basis in the home cage and in the test chamber. Measurements were taken of bar pressing, food and water intake during the $3-\mathrm{hr}$. test sessions, and water intake during the 21-hr. home cage periods. Each FR condition was run to stability. The criteria for stability was that each S's total bar-presses and 3-hr. water intake on the last three days of each FR condition were within the range obtained during the preceding six days of that condition. The data presented in this report are based entirely upon each S's performance in the last three days of each FR condition. The FR1 condition served as a baseline from which changes in meal length, number of meals, and $\mathrm{ml}$ of water ingested were evaluated.

\section{Results and Discussion}

The main results of the experiment are summarized in Fig. 1 where mean reinforcements, mean meals, and mean $\mathrm{ml}$ of water ingested by each $\mathrm{S}$ during the 3-hr. test sessions and the 21-hr. home cage periods, are shown as function of magnitude of the FR requirement. Four major points may be made from this data. First, water intake in the home cage varied inversely with test sessions water intake. This finding agrees with Falk (1964) and is apparently related to homeostatic mechanisms that regulate total daily water intake.

Second, 3-hr. water intake showed a relatively systematic increase for all Ss, except $S 3$, as the FR requirement increased. All Ss, including $S 3$, drank considerably more water under FR80 than under FR1. Mean $\mathrm{ml}$ of water drunk in the FR80 increased, from the FR1 baseline measurement, for Ss $1,2,3,4,5$, and 6 by $127,69,58,192,80$, and 420 per cent respectively. Furthermore, water consumption in the 3-hr. FR80 condition for all Ss approximated and, in some Ss, exceeded total 24-hr. water intake under the FR1 condition.

Third, number of meals increased as the FR requirement increased. For the present analysis, criteria were used which permitted each $\mathrm{S}$ to define meal length in terms of its behavior. Specifically, a meal was defined as any number of reinforcements which 




Fig. 1. Mean reinforcements, meals, and $\mathrm{ml}$ water ingested in the test sessions, and mean $\mathrm{ml}$ water ingested in the home cage periods, as a function of $F R$ requirements.

were terminated by drinking. This definition was specific to each $S$ and independent of the number of reinforcements ingested per meal. This particular definition was used since an analysis of the data indicated that all Ss ate some number of reinforcements, drank, paused, then ate, drank, paused, etc. Since number of meals and number of $\mathrm{ml}$ ingested both increased as the FR requirement increased, the present data are conceptually consistent with Stein's (1964) prandial drinking interpretation of increased water intake associated with reinforcement schedules.

Fourth, as the FR requirement increased beyond 20, total number of pellets obtained in the $3-\mathrm{hr}$. test session decreased. The significance of the increased water intake shown in Fig. 1 is made even more evident in Table 1 where a ratio between mean number of pellets ingested and mean $\mathrm{ml}$ of water consumed in the last three sessions of each FR condition is presented. As may be seen from this table, there was a general inverse relation between the ratio and size of the FR requirement. Thus, although the Ss were in

Table 1. Ratio of mean pellets eaten per $\mathrm{ml}$ of water ingested in the last three sessions of each FR condition

\begin{tabular}{ccccccc} 
FR Requirement & S 01 & S 02 & S03 & S 04 & S 05 & S 06 \\
\hline FR1 & $35: 1$ & $29: 1$ & $24: 1$ & $24: 1$ & $22: 1$ & $75: 1$ \\
FR5 & $23: 1$ & $10: 1$ & $15: 1$ & $17: 1$ & $22: 1$ & $32: 1$ \\
FR10 & $24: 1$ & $24: 1$ & $16: 1$ & $23: 1$ & $19: 1$ & $24: 1$ \\
FR20 & $16: 1$ & $20: 1$ & $19: 1$ & $16: 1$ & $16: 1$ & $27: 1$ \\
FR40 & $15: 1$ & $19: 1$ & $20: 1$ & $10: 1$ & $16: 1$ & $23: 1$ \\
FR80 & $8: 1$ & $11: 1$ & $15: 1$ & $7: 1$ & $11: 1$ & $11: 1$ \\
\hline
\end{tabular}

general obtaining fewer reinforcements as the FR increased, they were eating more meals, drinking more water per pellet, and increasing their total water intake as the FR requirement increased.

Although these results are consistent with Stein's (1964) interpretation of schedule-induced increases in water intake, Clark (1962) suggested that the effect depends on adventitious reinforcement. If this were the case, then there should have been a consistent pattern of alternation between drinking and bar-pressing, with drinking always immediately preceding bar-pressing. An examination of the data showed this was not the case: drinking followed, rather than preceded, bar-pressing. Although adventitious reinforcement may influence collateral water drinking in time-dependent schedules, it is apparently an insignificant factor in responsedependent schedules.

\section{References}

Clark, F. C. Some observations on the adventitious reinforcement of drinking under food reinforcement. J.exp. Anal. Behav, 1962, $5,61-63$.

Falk, I. L. The behavioral regulation of water-electrolyte balance. Nebraska symposium on motivation. Lincoln: Univ, of Neb. Press, 1961.

Falk, J. L. Studies on schedule-induced polydipsia. In M. J. Wayner (Ed.), Thirst. New York: Macmillan, 1964. Pp. 95-116.

Segal, E. F., \& Holloway, S. M. Timing behavior in rats with water drinking as a mediator. Science, 1963, 140, 883-889.

Stein, L. Excessive drinking in the rat: Superstition or thirst? J. comp. physiol. Psychol., 1964, 58, 237-242.

Note

1. Supported in part by Public Service Research Grants MH 08795 and MH 08775 from the National Institute of Mental Health. 